\title{
User evaluation of the APP NAS software in intensive care unit
}

\author{
Rosilene da Silva $^{1,2} \cdot$ Daniel Souza Ferreira Magalhães ${ }^{1}$ (D)
}

Received: 9 July 2020 / Accepted: 9 February 2021 / Published online: 22 February 2021

(C) Sociedade Brasileira de Engenharia Biomedica 2021

\begin{abstract}
Purpose The Nursing Activities Score (NAS) is a management tool that measures nursing workload, quantifying the care and the degree of complexity involved in the assistance, and can subsidize the managers for an adequate dimensioning of the team.

Objective The objective of this study is to evaluate impressions of users who work in the intensive care unit (ICU) of APP NAS in the APP and WEB modules, comparing them with classical methods of score evaluation: printed paper (PP) and/or spreadsheet (SS).

Methods This was a longitudinal, quantitative-descriptive study with professional nurses working in the intensive care of a University Hospital in Brazil. For the assessment test, the quality assessment process model was used, according to the NBR ISO / IEC 9126-1 standard employing the Questionnaire for User Interaction Satisfaction (QUIS). The research participants were nurses and nursing residents $(n=9)$ working in an ICU for at least 3 months in the institution. QUIS allows the evaluation of the following domains by grouping questions for each study group: general impressions, functionality, reliability, usability, efficiency, and maintainability.

Results Statistically significant satisfaction scores $(p<0.05)$ were observed in APP NAS when comparing to the classical methods (PP and SS) in the evaluated characteristics except for reliability.

Conclusion Our data showed broad approval of the APP NAS when comparing to classical methods making the software viable for implementation in ICUs of hospitals.
\end{abstract}

Keywords Nursing Activities Score $\cdot$ Mobile application $\cdot$ ICU $\cdot$ Workload $\cdot$ Software evaluation $\cdot$ Bioengineering

\section{Introduction}

Technological innovations have frantically impacted the health area. We live in the era of the digitalization of everyday life, and technology is increasingly present in the life of everyone, including in health institutions, reaching great proportions due to the growing pressure of demand and universal health access (Sitton-Kent et al. 2018; van Houwelingen et al. 2017). Across the world, the acceleration of technological development has been impacted by scientific, technological, and innovation development in health and contemporary social changes. The incorporation of innovative technologies in health care in the hospital and the ways to achieve improvements in this process

Daniel Souza Ferreira Magalhães

dsfmagalhaes@gmail.com

1 Scientific and Technological Institute, Universidade Brasil, São Paulo, Brazil

2 João de Barros Barreto University Hospital, Universidade Federal do Pará, Belém, Brazil have achieved unprecedented advances in processes and products to improve the quality of health services, based on better care, more resolute, and more responsible (Lima and Brazorotto 2020).

In the intensive care unit (ICU), it has never been more evident that technological advancement is essential to provide qualified assistance to critically ill patients and requires the availability of highly complex material resources and specialized human resources for safe assistance (Baggiol et al. 2010; Carayon et al. 2015; Hoekstra et al. 2009; Mezzaroba et al. 2009).

In particular, according to the Ministry of Health of Brazil, the process of incorporating new health technologies has collaborated in the choice of more suitable products, rationalizing expenses, and selecting technologies that offer more benefits to the population (Brasil 2017).

In this context, the Nursing Activities Score (NAS) has been used in ICUs in several countries, especially in Brazil, as it is a comprehensive instrument that measures the real nursing workload in the ICU, quantifying care and the degree of complexity involved (Bruyneel et al. 2019; Miranda et al. 
2003; Nieri et al. 2018). Besides, to be a reliable instrument from the research point of view, it can support managers for an adequate dimensioning of the nursing team in an objective way (Macedo et al. 2016; Inoue and Matsuda 2009).

In several ICUs in Brazil, NAS has been performed in an electronic spreadsheet (such as Microsoft Excel) or by manually filling out a paper form, once a day, and after the $24 \mathrm{~h}$ of care provided, retrospectively. Thus, becoming vulnerable to criticism because it is based on care that may not correspond currently to the care required (Severino et al. 2010).

Over time, NAS computerized systems have been described. The NAS in personal digital assistant (PDA) type equipment was described in 2009 (Castro et al. 2009). In 2010, a NAS structure in mobile technology was presented using the instrument in retrospective form, after $24 \mathrm{~h}$ of the assistance provided (Silveira et al. 2010). In 2016, a NAS system was developed consisting of two modules (managerial and operational) and designed to run on the internet, on sites hosted on Google with cloud storage (Moraes et al. 2016). Consequently, the need to develop a device with identified dynamic was evidenced (Castro et al. 2009; Silveira et al. 2010; Moraes et al. 2016) allowing data collecting by the professionals who assist the patient, in each work shift, providing their prospective interpretation. Additionally, to make this tool a practical instrument for carrying out the NAS in Portuguese, the APP NAS (Magalhães and Silva 2018; Silva et al. 2020a) was developed enabling the use of the scale prospectively.

This study hypothesizes that the use of the APP NAS can optimize the information production process in a friendly way to nursing professionals. To test this hypothesis, we compared APP NAS to the use of NAS on printed paper (PP) or an electronic spreadsheet (SS).

In this sense, the objective of this study is to evaluate the NAS software based on the impressions of specialized health professionals. For this purpose, nurses were trained with the NAS APP in the ICU and the general user impressions, functionality, reliability, usability, efficiency, and maintainability of the software were evaluated and compared to the classical methods, PP and SS.

\section{Methods}

Study design This was a cross-sectional study with a quantitative and descriptive approach with professional nurses working in the ICU of a University Hospital, using the NAS software (APP and WEB modules).

Setting It was performed in the ICU of a State University Hospital in Belém (northern state of Pará, Brazil), a hospital specialized in infectious diseases. The ICU has seven active beds and continuous assistance from the nursing team in different work shifts. In this hospital, the NAS was performed on printed paper and using an electronic spreadsheet for the calculation of the number of professionals by NAS average. The training of users with the application took place in June 2019. The application of the form for evaluation and data collection occurred in July and August 2019.

Participants The professionals who were working for more than 3 months in the ICU were eligible for the study. They could be fixed, temporary, or participating in a nursing residency program with interest and availability to participate in the study. Employees who were on sick leave were excluded, in addition to those who, after being invited, did not feel safe or even constrained to participate in the research. As a result, eight nurses and one nursing resident $(n=9)$ were available, all of them nurses in the ICU sector of the hospital. The project was submitted to the Research Ethics Committee and approved under the protocol number 3,481,109.

Variables The data were collected through a printed questionnaire filled by the nurses. To characterize the sample, the sociodemographic and work profile of the ICU professionals were described as sex, age, educational level, work title or function, acting time in the current function, weekly workload, and prior computer knowledge. To evaluate the software, the Questionnaire for User Interaction Satisfaction (QUIS) was followed according to ISO/IEC-25010 (2011). QUIS is a questionnaire validated and available in five languages, developed by a team of researchers from the Human Computer Interaction Laboratory, University of Maryland - College Park, United States of America (USA) (Shneiderman and Plaisant 2010). QUIS questions evaluate the following domains: general impressions, functionality, reliability, usability, efficiency, and maintainability. Functionality is the system's ability to perform user-oriented functions (ISO/IEC-14598-6 2001). Reliability is a relevant attribute that demonstrates the system's ability to maintain itself stable and acceptable performance in carrying out activities, even in adverse situations, when the flow of use is much above the usual average (ISO/IEC-14598-6 2001). The usability attribute is the ability of the system to be assimilated, used and intuitive; and the ability to offer the user the possibility to perform tasks efficiently and effectively (ISO/IEC-14598-6 2001). Efficiency is the ability to provide adequate performance when requested, even under adverse situations (ISO/IEC14598-6 2001). Maintainability is the ability to be modified and updated. Error corrections, adaptations, improvements, and new evolutionary demands are part of this attribute (ISO/ IEC-14598-6 2001), and this set of activities is known as system maintenance. Each question had a total of nine-point ordinal scale (where $1=$ very bad and $9=$ very good) allowing the evaluation of the information presented on the screens, terminologies, information systems, learning, and system capacity 
(Sauro and Lewis 2012). The variable "general impressions" was accessed by 6 questions, "functionality" by 3 questions, "reliability" by 2 questions, "usability" by 10 questions, "efficiency" by 3 questions, and "maintainability" by 3 questions (ISO/IEC-14598-6 2001; ISO/IEC-25010 2011). For each variable, the mean score value of the corresponding questions was considered to represent each participant in such a way that each studied group (SS, PP, APP, and WEB) was composed of nine values $(n=9)$.

Bias control The same smartphone model was used in the research and training with all participants, to eliminate differences between users' cell phones. Users have been trained in its use. For training, two leaflets with simple language, illustrative, and explanatory about the APP and WEB modules were used. At the end of the training, the participants were also reminded about the importance of answering the questions comparing each group (APP, WEB, PP, and SS) with their real impressions.

Statistical methods Data were represented using boxplots showing the median and interquartile range of the score of their domains with whiskers representing 5-95 percentile. Nonparametric statistics were used for the analysis because the results of the QUIS were discrete ordinal variables. For inferential analysis, we used the Friedman test with Dunn's post hoc test. Statistical significance was considered when $p<$ 0.05. Prism 5.0 and R-studio 1.1 were used for graphs and data analysis.

\section{Results}

The age of the participants was in a range between 30 and 40 years (min-max), with eight females $(88.8 \%)$, seven specialists $(78 \%)$, and with average (standard deviation) weekly workload of 38(9) h. Four nurses had been working in the ICU for 1 to 10 years $(44 \%)$, three working for 11 to 20 years (34\%), and two for more than 20 years (22\%). Only one nurse declares himself without no informatics knowledge (11\%).

User training was carried out with explanation in class and presentation of explanatory slides of the NAS scale, about the APP and WEB modules. A practical section was also performed with the explanatory leaflets created for new users and with direct visualization of the smartphone screens. Using the same Android smartphone model, the training users admitted patients to the app; then they explored the WEB module, viewing the reports generated from admitted patients, as well as registering and consulting patients, nurses, and beds. The total training lasted around $1 \mathrm{~h}$.

After training, participants inserted patients into the system through the APP module and performed NAS evaluation. Then, on the WEB platform, they were able to access this previously entered data and issue reports. The same smartphone model was used with all participants, to eliminate differences between users' cell phones.

At the end, the participants answered the questionnaire questions as shown in the previous section of this paper. The responses were grouped in order to assess the domains: general impressions, functionality, reliability, usability, efficiency, and maintainability (ISO/IEC-25010 2011).

In the first domain, general impressions, it was noticed that the Web module (WEB) had significantly higher score (*) than the spreadsheet method (SS). APP and WEB Modules had a significantly better evaluation $\left(^{\#}\right)$ than the paper method (PP) (Fig. 1).

In the functionality domain, the Web module (WEB) had significantly higher score $(*)$ than the paper method (PP) (Fig. 2).

In the reliability domain, no statistical difference between methods was confirmed, but a tendency of significance was noted ( $p=0.111$ ) (Fig. 3). Because questions in QUIS questionnaire related to this domain were not appropriated to the paper method evaluation (the questions are related to error messages), it was not considered in this evaluation.

In the usability domain of APP NAS, it was noticed that the module Web (WEB) had significantly higher score than the paper (PP) $(*)$ and spreadsheet (SS) $\left(^{\#}\right)$ methods (Fig. 4).

In the efficiency domain, the Web module (WEB) had significantly higher score than the paper (PP) $(*)$ and spreadsheet (SS) $\left(^{\#}\right)$ methods (Fig. 5).

In the maintainability domain, it was noticed that the Web module (WEB) had significantly higher score than the paper (PP) $(*)$ and spreadsheet (SS) $\left(^{*}\right)$ methods (Fig. 6). App module (APP) shows a tendency in significance as compared to PP $(p=0.08)$ and SS $(p=0.059)$.

\section{General impressions}

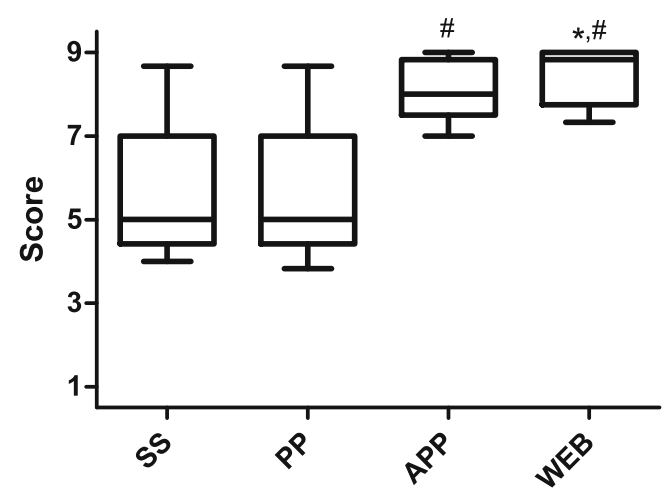

Fig. 1 General impressions of the users. Modules APP (APP) and Web (WEB) of the software APP NAS had a significantly higher user impression score than the paper (PP). Web module had its score higher than the spreadsheet (SS) method. * $p<0.05$ compared to $\mathrm{SS} ;{ }^{*} p<0.05$ compared to PP 


\section{Functionality}

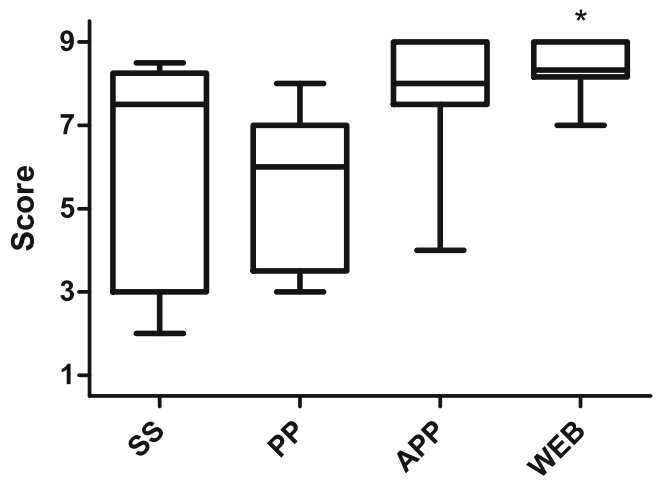

Fig. 2 Functionality of the methods. Web module (WEB) had a significantly higher functionality score than the paper method (PP). * $p<0.05$ compared to PP

\section{Discussion}

Analyzing QUIS results, for the user's general impression, the APP and WEB modules (Silva et al. 2020a) presented user impression scores significantly higher than the paper and spreadsheet methods. In this sense, studies have shown that globalization and the advent of the internet have contributed to mobile applications gaining more and more space in the population, being appreciated by the users (Diniz et al. 2019).

In the functionality domain, the Web module (WEB) had a score significantly higher than the paper method (PP). The responses in both WEB and APP modules of the different participants were mostly in score eight to nine (maximum value). This shows the potential of digital mobile technologies applied to health care, expanding the concept of care environment (Gama and Tavares 2019). Another study commented that the development of mobile applications incorporated into scientific research is an important tool for assistance, due to the process of analysis and testing with professionals who know the real needs of end users (Souza et al. 2020), improving the software functionality.

In the reliability domain, no statistical difference between methods was confirmed, but a tendency of

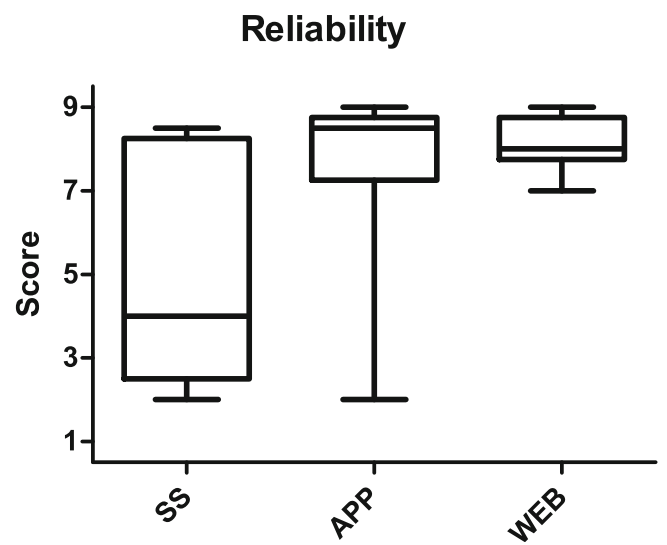

Fig. 3 Reliability of the methods. No statistical difference between methods was confirmed

\section{Usability}

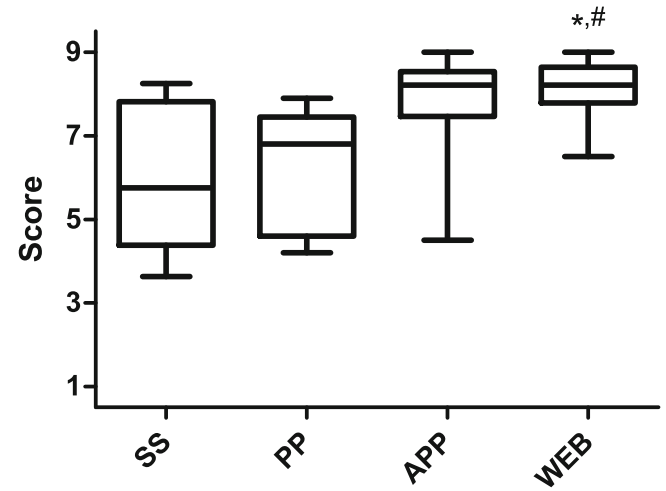

Fig. 4 Usability of the methods. Web module (WEB) had a significantly higher usability score than the paper (PP) and the spreadsheet (SS) methods. * $p<0.05$ compared to SS; ${ }^{*} p<0.05$ compared to PP

significance was noted and could be confirmed increasing the number of participants. Research carried out in the UK shows that smartphones have been strongly present in the life of the general population; moreover, such devices have been used routinely among health professionals as a way to improve communication in the hospital environment (Raiman et al. 2017; Rodis et al. 2016). A recent study that evaluated reliability shows that information technologies contribute to the work process of nursing professionals, computerizing the process in nursing and bringing reliability to the data record (Silva et al. 2020b).

In the usability domain, the Web module (WEB) had a significantly higher score than the paper and the spreadsheet methods. One of the biggest concerns in the development of mobile applications is the usability; therefore, taking into account the defined objectives and the needs of users, the usability evaluation intends to verify if there is an acceptable level of interface quality. Although there has been an exponential increase in the number of eHealth apps, the number of studies that have been published that report the results of usability testing on these apps has not increased at an equivalent rate. The number of digital

\section{Efficiency}

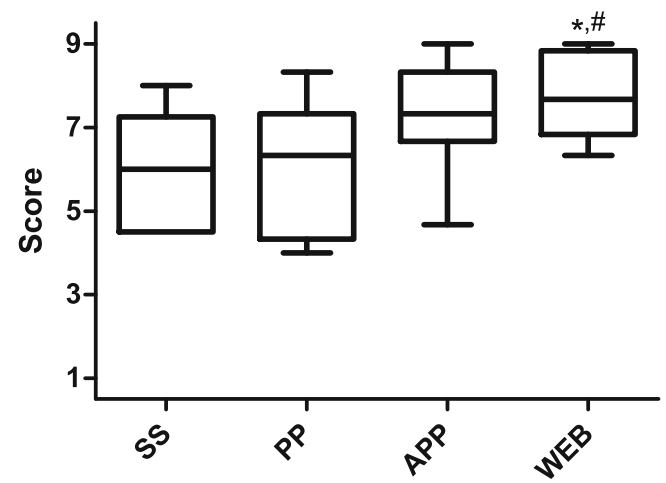

Fig. 5 Efficiency in the use of the methods. Web module (WEB) had a significantly higher efficiency score than the paper (PP) and the spreadsheet (SS) methods. ${ }^{*} p<0.05$ compared to SS; ${ }^{\#} p<0.05$ compared to PP 


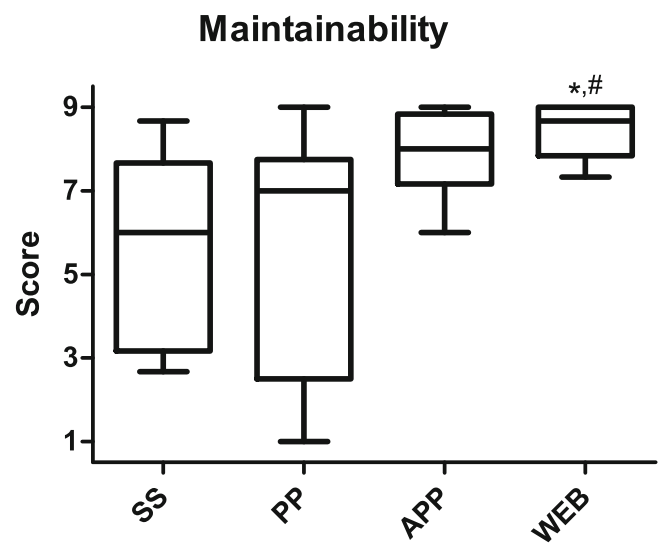

Fig. 6 Maintainability of the methods. Web module (WEB) of the software APP NAS had a significantly higher maintainability score than the paper (PP) and the spreadsheet (SS) methods. $*<0.05$ compared to SS; $\# p<0.05$ compared to PP

health applications that publish their usability evaluation results remains only a small fraction (Jakob 1994; Maramba et al. 2019).

In the efficiency domain, the NAS WEB presented an efficiency score significantly higher than the paper and the spreadsheet methods. Mobile applications break the limitation of mobility favoring the work of nurses in hospital environment; studies show the application as a tool that can document nursing actions, in addition to supporting decision-making (Silva et al. 2015). A recent study shows that the performance efficiency when evaluated in the real scenario of its use can be even better by applying the software directly in clinical practice (Felipe et al. 2020).

In the maintainability domain, the NAS WEB presented scores significantly higher than the paper and the spreadsheet methods, and the APP module showed a tendency in significance. Due to the changes that occur frequently in health knowledge, the maintenance of health information systems usually requires the dedication of great effort and time on the part of the responsible professionals and is usually responsible for a large part of the costs of developing programs (Atalag et al. 2012).

The health crisis generated by the new coronavirus (COVID19) has deeply changed the contemporary way of life around the world - with consequences that no one can yet say how long they will last (Du et al. 2020). With the pandemic, the importance of optimization and allocation of resources by managers of intensive care units (ICUs) was confirmed (Liew et al. 2020). It has never been more evident that technological advancement is essential in order to provide qualified assistance to critically ill patients and requires availability of highly complex material and specialized human resources for safe assistance (Phua et al. 2020). The APP NAS and NAS WEB are valuable tools for measuring workload helping in managing the workload in ICUs.

As a limitation of the study, we have the fact that the study was carried out in only one hospital and with a small sample of professionals $(n=9)$. An evaluation in other hospitals could reinforce our findings. Also, the assessment was made only by
ICU professionals, and a future study could evaluate the application in other areas of nursing. Another important aspect that could influence a slightly low score in the APP module as compared to the Web module, which did not bring statistical significance to APP as compared to paper and spreadsheet methods, is the fact that the nurses used all the same smartphone and there is usually some difficulty when using a device other than the one owned.

In this study, we evaluate the NAS software based on the impressions of specialized health professionals in the domains of functionality, reliability, usability, efficiency, and maintainability. Our results indicate significantly better approval of professionals than the traditional data collecting methods (paper and spreadsheet).

\section{Conclusion}

In this work, we evaluate and compare to classical methods the general user impressions and the domains: functionality, reliability, usability, efficiency, and maintainability of the software APP NAS with two modules (APP and WEB) developed to perform the Nursing Activities Score in intensive care unit. Our data showed broad approval of the APP NAS when comparing to classical methods making the software viable for implementation in ICUs of hospitals.

\section{Declarations}

Ethical approval All procedures performed in studies involving human participants were in accordance with the ethical standards of the institutional and/or national research committee and with the 1964 Helsinki declaration and its later amendments or comparable ethical standards.

Conflict of interest The authors declare no competing interests.

\section{References}

Atalag K, Yang HY, Warren J. Assessment of software maintainability of open EHR based health information systems - a case study in endoscopy. Electro J Health Infor. 2012;7(1):1-10.

Baggiol MA, Erdmann AL, Sasso GTM. Cuidado humano e tecnologia na enfermagem contemporânea e complexa. Texto contexto enferm. 2010;19(2).

Brasil. Ministério da Saúde. Secretaria de Ciência, Tecnologia e Insumos Estratégicos. Departamento de Gestão e Incorporação de Tecnologias em Saúde. Diretrizes metodológicas: avaliação de desempenho de tecnologias em saúde. 2017. Available at: http:// conitec.gov.br/images/Artigos_Publicacoes/Diretrizes/DIRETRIZ AdTS_final_ISBN.pdf. Accessed 22 Feb 2021

Bruyneel A, Tack J, Droguet M, Maes J, Wittebole X, Miranda DR, et al. Measuring the nursing workload in intensive care with the Nursing Activities Score (NAS): a prospective study in 16 hospitals in Belgium. J Crit Care. 2019;54:205-11. https://doi.org/10.1016/j. jcrc.2019.08.032. 
Carayon P, Wetterneck TB, Alyousef B, Brown RL, Cartmill RS, McGuire $\mathrm{K}$, et al. Impact of electronic health record technology on the work and workflow of physicians in the intensive care unit. Int J Med Inform. 2015;84(8):578-94. https://doi.org/10.1016/j.ijmedinf.2015.04.002.

Castro MCN, Dell'Acqua MCQ, Corrente JE, Zornoff DCM, Arantes LF. Aplicativo informatizado com o nursing activities score: Instrumento para gerenciamento da assistência em Unidade de terapia intensiva. Texto Contexto Enferm. 2009;18(3):577-85.

Diniz CM, Leal LP, Guedes TG, Linhares FM, Pontes CM. Contribuições dos aplicativos móveis para a prática do aleitamento materno: revisão integrativa. Acta Paul Enerm. 2019;32(5):571-7. https:// doi.org/10.1590/1982-0194201900079.

Du Z, Wang L, Cauchemez S, Xu X, Wang X, Cowling BJ, et al. Risk for transportation of 2019 novel coronavirus disease from Wuhan to other cities in China. Emerg Infect Dis. 2020;26(5):1049-52. https://doi.org/10.3201/eid2605.200146.

Felipe GF, Lima FET, Barbosa LP, Moreira TMM, Joventino ES, Freire VS, et al. Evaluation of user embracement software with pediatric risk classification. Rev Bras Enferm. 2020;73(3):e20180677. https:// doi.org/10.1590/0034-7167-2018-06.

Gama LN, Tavares CMM. Desenvolvimento e avaliação de aplicativo móvel na prevenção de riscos osteomusculares no trabalho de enfermagem. Texto contexto - enferm. 2019;28:e20180214. https://doi.org/10.1590/1980-265x-tce-2018-0214.

Hoekstra M, Vogelzang M, Verbitskiy E, Nijsten MW. Health technology assessment review: computerized glucose regulation in the intensive care unit how to create artificial control. Crit Care. 2009;13(5): 223. https://doi.org/10.1186/cc8023.

Inoue KC, Matsuda LM. Dimensionamento da equipe de enfermagem da UTI-adulto de um hospital ensino. Rev Eletr Enf. 2009;11(1):55-63.

ISO/IEC-14598-6:2001. Software engineering - Product evaluation - Part 6: Documentation of evaluation modules. 2001; https://www.iso. org/standard/24907.html Accessed 9 Jul 2020.

ISO/IEC-25010:2011. Systems and software engineering - Systems and software Quality Requirements and Evaluation (SQuaRE) - System and software quality models. 2011; https://www.iso.org/standard/ 35733.html Accessed 9 Jul 2020.

Jakob N. Usability inspection methods. In Conference companion on Human factors in computing systems 1994; https://doi.org/10. 1145/259963.260531.

Liew MF, Siow WT, MacLaren G, See KC. Preparing for COVID-19: early experience from an intensive care unit in Singapore. Crit Care. 2020;24:24(83). https://doi.org/10.1186/s13054-020-2814-x.

Lima RA, Brazorotto JS. Qual o status da incorporação de tecnologias em saúde no contexto hospitalar? R Bras Inov Tecnol Saúde. 2020; Available at: https://periodicos.ufrn.br/reb/article/view/18736. Accessed 22 Feb 2021

Macedo APMC, Mendes CMFS, Candeias ALS, Sousa MPR, Hoffmeister LV, Lage MIGS. Validação do Nursing Activities Score em Unidades de Cuidados Intensivos Portuguesas. Rev Bras Enferm. 2016;69(5):881-7.

Magalhães DSF, Silva R. APP NAS e NAS WEB - Aplicativo móvel para avaliação e planejamento da carga de trabalho de enfermagem utilizando o "Nursing Activities Score"; Gerenciamento em rede do APP NAS - APP para avaliação e planejamento da carga de trabalho de enfermagem utilizando o "Nursing Activities Score". INPI. BR512018052000-6 e BR512018051999-7; 2018.

Maramba I, Chatterjee A, Newman C. Methods of usability testing in the development of eHealth applications: a scoping review. Int J Med Inform. 2019 Jun;126:95-104. https://doi.org/10.1016/j.ijmedinf. 2019.03.018.

Mezzaroba RM, Freitas VM, Kochla KRA. O cuidado de Enfermagem ao paciente crítico na percepção da família. Cogitare Enferm. 2009;14(3):499-505.
Miranda DR, Nap R, de Rijk A, Schaufeli W, Iapichino G. Nursing Activities Score. Crit Care Med. 2003;31:374-82. https://doi.org/ 10.1097/01.CCM.0000045567.78801.CC.

Moraes KB, Martins FZ, Camargo MD, Vieira DF, Magalhães AMM, Silveira DT. Nursing Activities Score: cloud computerized structure. Nurs Inform. 2016. https://doi.org/10.3233/978-1-61499-658-3836.

Nieri AS, Manousaki K, Kalafati M, Padilha KG, Stafseth SK, Katsoulas $\mathrm{T}$, et al. Validation of the nursing workload scoring systems "Nursing Activities Score" (NAS), and "Therapeutic Intervention Scoring System for Critically Ill Children" (TISS-C) in a Greek paediatric intensive care unit. Intensive Crit Care Nurs. 2018 Oct;48:3-9. https://doi.org/10.1016/j.iccn.2018.03.005.

Phua J, Weng L, Ling L, Egi M, Lim CM, Divatia JV, et al. Intensive care management of coronavirus disease 2019 (COVID-19): challenges and recommendations. Lancet Respir Med. 2020. https://doi.org/10. 1016/S2213-2600(20)30161-2.

Raiman L, Antbring R, Mahmood A. WhatsApp messenger as a tool to supplement medical education for medical students on clinical attachment. BMC Med Educ. 2017;17:7. https://doi.org/10.1186/ s12909-017-0855-x.

Rodis J, Aungst TD, Brown NV, Cui Y, Tam L. Enhancing pharmacy student learning and perceptions of medical apps. JMIR Mhealth Uhealth. 2016;4. https://doi.org/10.2196/mhealth.4843.

Sauro J, Lewis JR. Quantifying the user experience: practical statistics for user research. 1st ed: Elsevier; 2012.

Severino R, Saiote E, Martinez AP, Deodato S, Nunes L. Nursing Activities Score: Índice de avaliação da carga de trabalho de enfermagem na UCI. Percursos. 2010;16 Available at: http://hdl. handle.net/10400.26/9208.

Shneiderman B, Plaisant C. Designing the user interface: strategies for effective human-computer interaction. 5th ed.: Pearson Education India; 2010.

Silva KL, Évora YDM, Cintra CSJ. Software development to support decision making in the selection of nursing diagnoses and interventions for children and adolescents. Rev Latino-Am Enfermagem. 2015;23:927-35. https://doi.org/10.1590/0104-1169.0302.2633.

Silva R, Baptista A, Serra RL, Magalhães DSF. Mobile application for the evaluation and planning of nursing workload in the intensive care unit. Int J Med Inform. 2020a;137:104120. https://doi.org/10. 1016/j.ijmedinf.2020.104120.

Silva WM, Mangueira SO, Silva ME, Silva TFM, Sanches LMP, Oliveira KML. Evaluation of the "Nursing Process Teaching Information System - SIEPENF" software. Res Soc Develop. 2020b;9(10): e539108220. https://doi.org/10.33448/rsd-v9i10.8220.

Silveira DT, Catalan VM, Neutzling AL, Martinato LHM, Borges GCM. Nursing Activities Score (NAS): development stages of a mobile system for nursing. J Health Inform. 2010;2(2):44-50.

Sitton-Kent L, Humphreys C, Miller P. Supporting the spread of health technology in community services. Br J Community Nurs. 2018;23(3):118-22. https://doi.org/10.12968/bjen.2018.23.3.118.

Souza JCO, Matos LBS, Galvão NS, Menezes SSC, Chaves TC, Pereira TC. Development of software for the evaluation and treatment of pressure injuries. Research, Society and Development. 2020;9(8): e995986687. https://doi.org/10.33448/rsd-v9i8.6687.

van Houwelingen CTM, Ettema RGA, Kort HSM, Ten Cate O. Internetgeneration nursing students' view of technology-based health care. J Nurs Educ. 2017;56(12):717-24. https://doi.org/10.3928/ 01484834-20171120-03.

Publisher's Note Springer Nature remains neutral with regard to jurisdictional claims in published maps and institutional affiliations. 